\title{
At the intersection of place, race, and health in Brazil: Residential segregation and cardio-metabolic risk factors in the Brazilian Longitudinal Study of Adult Health (ELSA-Brasil)
}

\author{
Sharrelle Barber ${ }^{a}$, Ana V. Diez Roux ${ }^{\text {a }}$, Letícia Cardoso ${ }^{\text {b }}$, Simone Santos ${ }^{\text {b }}$, Veronica Toste ${ }^{\text {, }}$ \\ Sherman James ${ }^{\mathrm{d}}$, Sandhi Barreto ${ }^{\mathrm{e}}$, Maria Schmidt ${ }^{\mathrm{f}}$, Luana Giatti ${ }^{\mathrm{e}}$, Dora Chor ${ }^{\mathrm{b},{ }^{*}}$ \\ ${ }^{a}$ Department of Epidemiology and Biostatistics, Drexel University Dornsife School of Public Health, Philadelphia, PA, United States \\ ${ }^{\mathrm{b}}$ Department of Epidemiology, National School of Public Health, Fundação Oswaldo Cruz, Rio de Janeiro, Rio de Janeiro, Brazil \\ ${ }^{c}$ Postgraduate Program in Sociology and Anthropology, Institute of Philosophy and Social Sciences, Universidade Federal do Rio de Janeiro, Rio de Janeiro, \\ Rio de Janeiro, Brazil \\ d Sanford School of Public Policy, Duke University, Durham, NC, United States \\ e Postgraduate Program in Public Health, Faculty of Medicine, Universidade Federal de Minas Gerais, Belo Horizonte, Minas Gerais, Brazil \\ ${ }^{\mathrm{f}}$ Postgraduate Program in Epidemiology, Universidade Federal do Rio Grande do Sul, Rio Grande do Sul, Porte Alegre, Brazil
}

\section{A R T I C L E I N F O}

\section{Article history:}

Received 8 November 2016

Received in revised form

20 May 2017

Accepted 23 May 2017

Available online $\mathrm{xxx}$

\section{Keywords:}

Racial health inequalities

Residential segregation

Hypertension

Diabetes

Brazil

\begin{abstract}
A B S T R A C T
Residential segregation is the spatial manifestation of entrenched socioeconomic and racial inequities and is considered a fundamental cause of racial inequalities in health. Despite the well-documented racialized spatial inequalities that exist in urban areas throughout Brazil, few empirical investigations have examined the link between residential segregation and health and considered its implications for racial health inequalities in this setting. In the present study, we used data from the Brazilian Longitudinal Study of Adult Health (2008-2010) to examine the association between economic residential segregation and two major cardio-metabolic risk factors-hypertension and diabetes. We also examined whether associations were stronger for historically marginalized racial groups in Brazil. Residential segregation was calculated for study-defined neighborhoods using the Getis-Ord Local $\mathrm{G}_{i}{ }^{*}$ statistic and was based on household income data from the 2010 IBGE demographic census. Multivariable logistic regression models were used to examine associations. In our sample, Blacks and Browns were more likely to live in economically segregated neighborhoods. After taking into account income, education, and other demographic characteristics we found that individuals living in the most economically segregated neighborhoods were $26 \%$ more likely to have hypertension and $50 \%$ more likely to have diabetes than individuals living in more affluent areas. Although Blacks and Browns living in highly segregated neighborhoods had higher prevalence of hypertension and diabetes compared to Whites, we observed no statistically significant racial differences in the associations with residential segregation. Our findings suggest that residential segregation may be an important structural determinant of cardio-metabolic risk factors in Brazil. Moreover, the systematic and disproportionate exposure of Blacks and Browns to highly segregated neighborhoods may implicate these settings as potential drivers of racial inequalities in cardio-metabolic risk factors in urban settings in Brazil.
\end{abstract}

(C) 2017 Elsevier Ltd. All rights reserved.

\section{Introduction}

Residential segregation- defined as the systematic separation

* Corresponding author. 1480 Leopoldo Bulhões St., Room 807, Rio de Janeiro, BR 21031-210, Brazil.

E-mail addresses: smb483@drexel.edu (S. Barber), dora.chor@fiocruz.br (D. Chor). of individuals into different neighborhoods based on social class and/or race - is considered a "fundamental cause" of racial health inequalities (Williams and Collins, 2001) and has received considerable attention in U.S.-based epidemiologic studies (for recent reviews see Kershaw and Albrecht, 2015; Krieger, 2014). The link between segregation and health has been explored for a number of health outcomes including cardio-metabolic risk factors (Kershaw and Albrecht, 2015) with most studies documenting stark 
inequalities along dimensions of race and class-based measures of segregation (Kershaw and Albrecht, 2015; Krieger, 2014; Krieger et al., 2015).

Although there are documented socioeconomic and racial health inequalities in Brazil, the consequences of segregation on health outcomes have not been sufficiently examined in this setting. A number of parallels between and distinctions from the U.S. make Brazil a particularly relevant context for investigation. First, like the U.S., Brazil shares the infamous legacy of slavery, importing 11 times more west and central Africans as slaves than the U.S. during its nearly 300-year history in the country (Telles, 2004a). As a result, Brazil has the largest African-descended population outside the continent of Africa with Blacks and Browns numbering 15 million and 82 million, respectively in 2010, more than half (50.7\%) of Brazil's 191 million inhabitants (IBGE, 2010). Secondly, though residential segregation in Brazil has most often been described and characterized as a by-product of "social class" as opposed to "race", documented racial inequalities in educational and job market opportunities (Marteleto, 2012) and racial discrimination (Antônio and Ribeiro, 2006; Hasenbalg, 1979; Telles and Lim, 1998) has resulted in a disproportionate number of nonWhites in economically segregated residential environments (Telles, 2004b). The over-representation of Blacks and Browns in these settings is a very visible manifestation of structural racism in Brazil that may implicate these settings as potential drivers of racial inequalities in health (Chor et al., 2015a).

Another important distinction is that racial classification in Brazil does not replicate the binary Black-White divide found in the U.S. and can be better understood as a racial continuum based on skin color that is commonly summarized as a ternary system composed of Blacks, Browns ('Pardos'), and Whites (Telles, 2014). As such, residential patterns in Brazil do not mimic the Black-White dichotomy found in many urban settings throughout the U.S. Finally, segregation in Brazil is often characterized by the "peripheralization" of the poor (mostly Blacks and Browns) which is distinct from the spatial patterning found in major cities in the U.S. in which poor communities of color are often concentrated in the inner-cities (Jargowsky, 2015; Massey and Denton, 1993; Wilson, 1987, 2009).

\subsection{Residential segregation in Brazil}

According to the 2010 census, the urban population in Brazil comprises almost 161 million people, upwards of $80 \%$ of the total Brazilian population (IBGE, 2010). Like most Latin American countries, the urban landscape in Brazil is characterized by multiple forms of intertwining, spatial inequalities (Angotti, 1996) - the byproduct of a complex set of historical, political, and economic factors (Telles, 1995, 2004b). Despite significant social advances of the last decade, the intra-metropolitan inequality levels captured by social indicators in Brazil are very acute; in the most extreme cases, some neighborhoods have median per capita incomes nearly 35 times higher than others (IBGE, 2010).

The most resilient and pervasive trait of Brazilian cities is the peripheralization of the poorest segments of the population who are often segregated into distant neighborhoods on the outskirts of major metropolitan areas. Since the provision of urban services is closely linked with social class, these residentially segregated areas are poorly served by public infrastructure, lack basic public amenities and are less integrated into the economic circuits of the city (de Carvalho and Pereira, 2007). In contrast, medium and high income classes usually concentrate in residential areas closer to jobs, educational opportunities, leisure activities, transport options and public services.

The roots of segregation in Brazil are complex, but can be traced back to the last quarter of the nineteenth century, when poor and former enslaved people sought opportunities of life and work in the cities, building and occupying improvised stilt houses, shacks, and tenements (Theodoro, 2008). The phenomenon became more accentuated and started to assume its present form mostly since the 1940s. It was by then that urbanization processes accelerated and massive migrations from rural to urban areas took place in Brazil, changing it dramatically from a rural to an urban nation (Ermínia Maricato, 2010; L. Ribeiro and Katzman, 2008). The rapid growth of the cities was not accompanied at an equal pace by investments in basic infrastructure such as piped water, basic sanitation, energy supply and asphalt paving. Consequently, one of the remnants of this process is the existence of large networks of informal or "illegal" arrangements known as "favelas" that emerged as a matter of necessity for the poor in the face of inaction by the State and the private housing sector's economic interests (Ermínia Maricato, 2010; P. Torres et al., 2016). Over time, the lack of sustained urban planning and public housing programs as well as limited State control over the housing market has served to maintain these spatial inequalities.

However, segregation in Brazil not only reflects inequalities based on social class but is also a reflection of the historical geographic segregation of the Afro-descended population into less developed sections of urban areas (L. Ribeiro et al., 2009; Telles, 1992; Theodoro, 2008). Across the urban landscape in Brazil, Blacks and Browns are disproportionately represented in economically segregated neighborhoods, due in large part to inequalities in educational and job market opportunities (Antônio and Ribeiro, 2006; Osorio, 2009; C. Ribeiro, 2012). For example, though Blacks and Browns make up 50\% of the population, they comprise upwards of $70-80 \%$ of residents in some of the most economically segregated neighborhoods in the country (Gusmão, 2015). Moreover, Blacks and Browns who have achieved middleclass status have been largely excluded from the most affluent areas due to inequities in accumulated wealth and discrimination which limits their mobility out of economically segregated neighborhoods (Erminia Maricato, 2013; Rocha et al., 2016). In short, residential segregation in Brazil represents interconnected economic and racial inequalities that may have profound implications for health and health inequalities.

\subsection{At the intersection of place, race, and health in Brazil}

In $2012,30 \%$ of all deaths were attributable to cardiovascular diseases in Brazil (Brazil Health Ministry, 2013) making cardiometabolic risk factors such as hypertension and diabetes a major public health concern. High blood pressure is the leading risk factor for death and years of life lost in Brazil (Lim et al., 2012) and the country is ranked 4th globally in terms of the absolute number of persons with diabetes (NCD-RisC, 2016). Though a burgeoning literature exists on the influence of residential environments on cardiovascular disease and related risk factors broadly (Chaix, 2009; Diez Roux and Mair, 2010; Leal and Chaix, 2011), and residential segregation more specifically (Kershaw and Albrecht, 2015), explanations for the etiology of risk factors such as hypertension and diabetes in Brazil have mostly been limited to individual lifestyle factors related to diet and physical activity. Absent from these explanations are considerations of broader structural mechanisms such as economic segregation that may influence hypertension and diabetes through a number of pathways including limited access to economic and educational opportunities, limited access to healthpromoting resources and healthcare services as well as chronic exposure to a number of health-damaging social factors (Kramer and Hogue, 2009; White and Borrell, 2011; Williams and Collins, 2001). 
Using data from the Brazilian Longitudinal Study of Adult Health (ELSA-Brasil), we examined the cross-sectional association between economic residential segregation and hypertension and diabetes using the Getis-Ord Local $\mathrm{G}_{i}{ }^{*}$ statistic - a novel spatial approach to measuring neighborhood-level segregation. To our knowledge, no studies have examined economic segregation in relation to cardio-metabolic risk factors in Brazil and considered its implications for racial health inequalities in this setting. We hypothesized that economic segregation would be positively associated with hypertension and diabetes independent of sociodemographic characteristics. We also examined the extent to which associations differed by race. Given the marginalized racial status of Blacks and Browns in Brazil- which may compound the impact of segregation on hypertension and diabetes vis-à-vis other forms of institutional and interpersonal racism- we hypothesized that the impact of economic segregation would be stronger among these groups (Krieger, 2011). Finally, we explored whether specific features of the neighborhood environment and behavioral and biological risk factors partially explain observed associations.

\section{Methods}

\subsection{Study population}

ELSA-Brasil is a multicentre cohort study designed to examine the etiology of cardiovascular diseases and diabetes in Brazil, including their social, environmental, occupational and biological determinants (Aquino et al., 2012). The sample includes civil servants from 5 universities and 1 research institution located in six metropolitan areas in Brazil: Belo Horizonte, Porto Alegre, Rio de Janeiro, Salvador, São Paulo, and Vitória. All active or retired employees of the six institutions ages 35-74 years were eligible for the study and approximately equal proportions of unskilled, technical/ clerical, and faculty/professional staff were enrolled. The study population is also heterogeneous with regard to race and includes Whites (52\%), Browns (28.2\%) and Blacks (16.1\%) as well as Indigenous and Asian groups (<5\%) (Schmidt et al., 2015).

The baseline examination for the study took place from August 2008 to December 2010 and included extensive clinical examinations as well as in-person interviews conducted by trained personnel (Bensenor et al., 2013; Chor et al., 2013). Information abstracted from the mailing address provided during the baseline interview was used to geocode participants to their census tract of residence (98.2\%). More detailed information - including design, sources and methods of recruitment- have been described in detail elsewhere (Aquino et al., 2012; Schmidt et al., 2015). The study was approved by the Research and Ethics Committees of the institutions involved and all participants signed declarations of informed consent.

The analytic sample for this study included all ELSA-Brasil participants with geocoded information who self-identified as Black, Brown, or White and resided in the metropolitan boundaries of the six study sites $(\mathrm{n}=11,049)$. Individuals were excluded if they had missing data on hypertension and diabetes $(n=17)$ and key covariates $(n=415)$. The resulting analytic sample was comprised of 10,617 participants residing in 1848 study-defined neighborhoods.

\subsection{Measures}

\subsubsection{Residential segregation}

Local neighborhood environments were based on study-defined boundaries which were created for each site using a spatial aggregation method based on SKATER (Spatial 'K'luster Analysis by Tree Edge Removal). This method was used to create clusters of contiguous census tracts that had a minimum population size of 5000 inhabitants and were homogenous with regard to four socioeconomic indicators from the 2010 Brazilian Institute of Geography and Statistics (IBGE) demographic census (IBGE, 2010): the proportion of the population $0-4$ years of age; household size; mean household income; and the proportion of Whites (Santos et al., 2010). This geographic scale is comparable in size to U.S. census tracts which are commonly used proxies in neighborhood effects research (Krieger, 2006).

Economic residential segregation was assessed for all studydefined neighborhoods located within the metropolitan boundaries of the six ELSA-Brasil sites. We chose to use economic segregation as opposed to race, because social class is more commonly used in Brazil and because the complexities of Brazilian racial classification make it difficult to transpose commonly used measures of racial residential segregation from the U.S. context to this setting. We used the Getis-Ord Local $\mathrm{G}_{\mathrm{i}}{ }^{*}$ statistic (hereafter, $\mathrm{G}_{\mathrm{i}}{ }^{*}$ statistic) (Getis and Ord, 1992), a novel spatial approach that has been used in recent epidemiologic investigations of segregation and cardiovascular disease (Kershaw et al., 2015). The $\mathrm{G}_{\mathrm{i}}{ }^{*}$ statistic is a spatially-weighted z-score that represents how much a neighborhood's income composition deviates from the larger metropolitan area. Unlike more commonly used measures of segregation such as the dissimilarity index and the isolation index which are used to characterize segregation for larger geographic units (e.g. metropolitan areas) (Massey and Denton, 1988), this measure captures segregation at the neighborhood-level which allows for the examination of segregation within metropolitan areas (Kershaw and Albrecht, 2015) and the exploration of more localized mechanisms linking residentially segregated environments to cardiometabolic risk factors. Moreover, the $\mathrm{G}_{\mathrm{i}}{ }^{*}$ statistic improves upon past neighborhood measures of segregation, which have generally relied on racial or socioeconomic composition as crude approximations of local segregation, by accounting for the spatial clustering of segregation (i.e. poor neighborhoods surrounded by other poor neighborhoods will have higher values) and the income composition of the larger metropolitan area in which the neighborhood is embedded. The latter is particularly important because a neighborhood with a compositional value of $50 \%$ poor means a very different thing in terms of segregation if the city as a whole is $5 \%$ poor (the neighborhood is therefore highly segregated) than if $50 \%$ of the overall population is poor (the neighborhood is not segregated at all).

For the present study, the $\mathrm{G}_{i}{ }^{*}$ statistic was based on the proportion of heads of households in a neighborhood earning a monthly income of $0-3$ minimum wages (i.e. up to 3 times the minimum wage or approximately $\$ 900$ USD in 2010) and was derived using data from the 2010 IBGE census (IBGE, 2010). The decision to use 3 minimum wages as the cut-point was based on prior studies of economic segregation in Brazil $(\mathrm{H}$. d. G. Torres, 2006). $\mathrm{G}_{\mathrm{i}}{ }^{*}$ scores were calculated for neighborhoods in each ELSA site separately using the Hot Spot Analysis Tool in ArcGIS ${ }^{\circledR}$, version 10.3 and based on the following equation:

$$
G_{i}^{*}=\frac{\sum_{j=1}^{n} w_{i, j} x_{j}-\bar{X} \sum_{j=1}^{n} w_{i, j}}{S \sqrt{\frac{\left[n \sum_{j=1}^{n} w_{i, j}^{2}-\left(\sum_{j=1}^{n} w_{i, j}\right)\right]}{n-1}}}
$$

Where $x_{j}$ represents the proportion of households with 0-3 minimum wages for neighborhood $j ; w_{i j}$ is the spatial weight between feature $i$ and $j, n$ is the total number of neighborhoods within the metropolitan area, $\bar{X}$ is the mean proportion of households with $0-3$ minimum wages for the metropolitan area, and $S$ is the 
standard deviation (ESRI).

Neighboring tracts were weighted using a first order rook spatial weight matrix to ensure consistency across study sites. Large, positive scores represent neighborhoods that are more segregated (i.e. higher proportion of households with $0-3$ minimum wages) while low negative scores represent neighborhoods that are less segregated (i.e. lower proportion of households with 0-3 minimum wages). Based on the distribution of the sample, we created categories of segregation that represent neighborhoods with segregation scores \pm 1 standard deviation above the metropolitan mean (High: $\mathrm{G}_{\mathrm{i}}{ }^{*}$ statistic $\geq 1$; Medium $\mathrm{G}_{\mathrm{i}}{ }^{*}$ statistic between 1 and -1 and Low: $\mathrm{G}_{\mathrm{i}}^{*}$ statistic $\leq-1$ ).

\subsubsection{Hypertension and diabetes}

Hypertension was defined as systolic BP $\geq 140 \mathrm{mmHg}$ or diastolic $\mathrm{BP} \geq 90 \mathrm{mmHg}$ or use of antihypertensive medication in the last two weeks (Chor et al., 2015b). Systolic and diastolic blood pressure (BP) was measured during the baseline examination after a 5 min rest with the participant in a sitting position in a quiet, temperature-controlled room. Three measurements were taken at 1-min intervals and mean systolic and diastolic BP of the second and third readings were calculated for each participant.

Diabetes mellitus at baseline was defined as self-reported diabetes, use of anti-diabetic medication or any of the following diagnostic criteria assessed using blood samples collected during the baseline examination: fasting plasma glucose $\geq 126 \mathrm{mg} / \mathrm{dL} ; 2 \mathrm{~h}$ plasma glucose after a 75 g glucose load $\geq 200 \mathrm{mg} / \mathrm{dL}$; or glycated hemoglobin $\geq 6.5 \%$ (Schmidt et al., 2015).

\subsubsection{Covariates}

Individual socio-demographic characteristics included age (in years), gender (male or female), race, per capita income (in Reais) and educational attainment. Race was based on self-report and categorized as Black, Brown, and White. Per capita household income was derived by dividing the midpoint of the self-reported household income category by the number of members in the household dependent on the income. Education was categorized as incomplete elementary school, completed elementary school; completed secondary school, and university degree.

Information on features of the social, physical, and food environment that may partially mediate the association between segregation and hypertension and diabetes (Diez Roux and Mair, 2010), was obtained using validated scales during the baseline examination (Santos et al., 2013). These scales were cross-culturally adapted from prior work in the Multi-Ethnic Study of Atherosclerosis (Mujahid et al., 2007) and validated in the study population.

The neighborhood social environment was assessed using two scales: social cohesion (e.g. "This is a close-knit or unified neighborhood", Cronbach's $\alpha=0.65$ ) and exposure to violence (e.g. "In the past six months, how often was there a robbery or mugging in your neighborhood?" Cronbach's $\alpha=0.73$ ). The neighborhood walking/physical environment was assessed using a 9-item scale (e.g. "It is pleasant to walk in my neighborhood", Cronbach's $\alpha=0.76$ ) and the neighborhood food environment was assessed using a 4-item scale (e.g. "A large selection of fresh fruits and vegetables is available in my neighborhood", Cronbach's $\alpha=0.79$ ). Items for each scale were summed to create overall scores with higher scores denoting worse perceived neighborhood physical and food environments. All scales of the neighborhood environment demonstrated moderate reliability and were consistent with past assessment in the study population (Chor et al., 2016; Santos et al., 2013).

Finally, we included health behaviors and biological risk factors that could confound or partially mediate the association between segregation and hypertension and diabetes: physical activity, daily total caloric intake, daily fat intake, smoking status, alcohol consumption, and obesity status. Physical activity was assessed using data from the International Physical Activity Questionnaire long form (Lee et al., 2011) and categorized based on the number of minutes per week participants engaged in physical activity-both leisure and transport-related- (no physical activity, <150 min/ week, $\geq 150 \mathrm{~min} /$ week) (Chor et al., 2016). Total daily caloric intake (in grams) and daily lipid intake (in kcal) were obtained using information from a 114-item food frequency questionnaire adapted for the study population (Molina et al., 2013). Smoking status was categorized as current, former, never. Alcohol consumption was assessed via questionnaire and was dichotomized as "high" according to the amount consumed per week (men $\geq 210 \mathrm{~g}$; women $\geq 140 \mathrm{~g}$ ). Body mass index (BMI) was calculated by dividing the patients' weight in kilograms by height in meters squared and obesity was categorized as a BMI $\geq 30 \mathrm{~kg} / \mathrm{m}^{2}$.

\subsection{Statistical analysis}

We examined the distribution of select study characteristics for the full sample, categories of segregation, and for hypertension and diabetes (Supplemental Table 2). Means and standard deviations were calculated for continuous variables and frequency distributions were calculated for categorical variables. Age and gender adjusted prevalence of hypertension and diabetes were calculated for the total population, categories of segregation and for crossclassified categories of segregation and race using the PROC GENMOD procedure.

To examine the association between segregation and hypertension and diabetes, we fit a set of sequential logistic regression models separately for each outcome. We also fit separate models that examined continuous and categorical specifications of segregation. Model 1 adjusted for age, race, and gender. To examine whether the association was independent of individual socioeconomic status, Model 2 further adjusted for family income and education. Finally, Models 3 and 4 adjusted for features of the neighborhood environment (included in models as tertiles) and behavioral and biological risk factors, respectively that may partially explain the association. All models also included indicator variables for study site to control for any site-specific confounders. To examine whether the association differed by race, we included interaction terms between segregation and race in regression models controlling for socio-demographic characteristics.

In sensitivity analyses, we ran generalized estimating equations (GEE models) to account for the clustering of individuals within neighborhoods using the same modeling procedure. We observed no changes in standard errors, likely due to the sparse distribution of participants across neighborhoods in the sample (median $=3$ ) and point estimates remained consistent across all models. Therefore, results from logistic regression models are reported. All analyses were carried out using SAS $^{\circledR}$ software, Version 9.3 (SAS $^{\circledR}$ Institute, Inc., Cary, NC).

\section{Results}

\subsection{Residential segregation in the ELSA-Brasil sample}

Segregation scores ranged from -6.85 to 3.48 and approximately $14 \%$ of the total sample $(n=1534)$ resided in highly segregated neighborhoods. Mean segregation scores were higher for Blacks and Browns compared to Whites (Fig. 1) and, consistent with general patterns of race and segregation in Brazil (see Supplemental Table 1). Blacks and Browns were more likely than Whites to reside in highly segregated neighborhoods (Blacks: 25.9\%; Browns: 20.2\%; Whites: 8.2\%, see Supplemental Fig. 1). We 


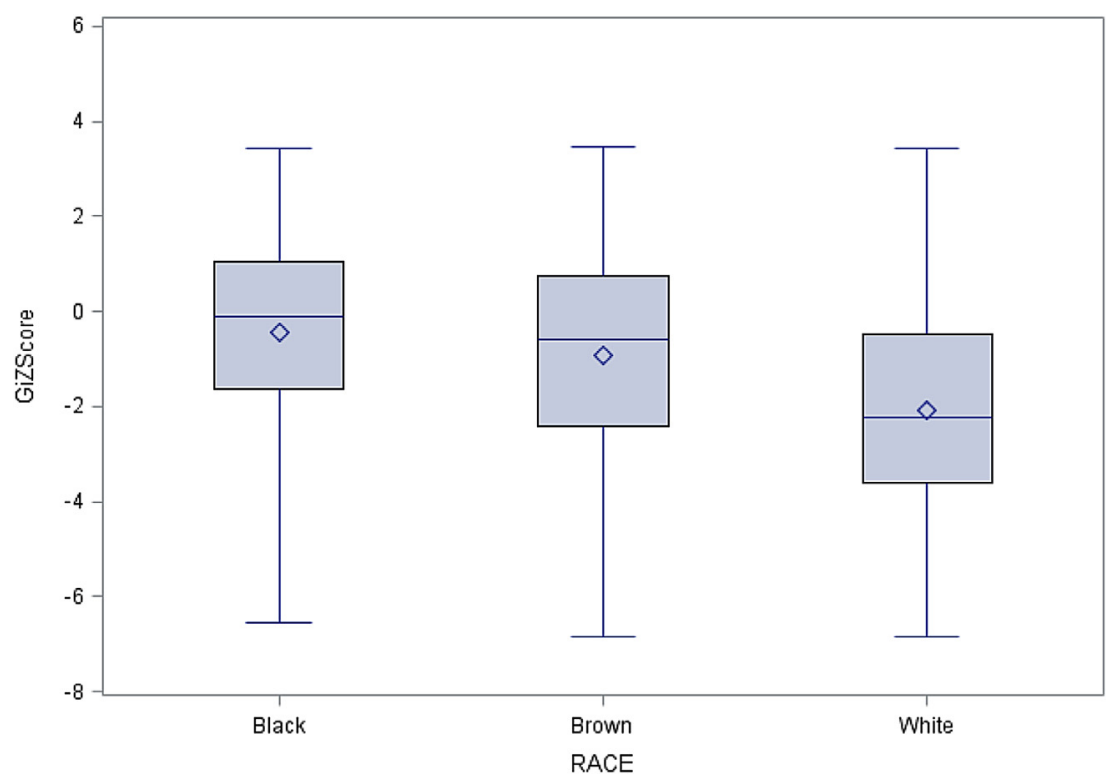

Fig. 1. Distribution of Residential Segregation by Race in ELSA-Brasil (2008-2010).

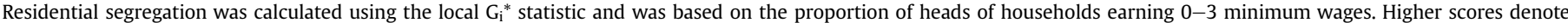

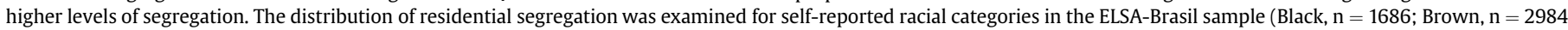
and White, $\mathrm{n}=5947)$ and was significantly higher for Blacks and Browns compared to Whites $(<0.0001)$.

also observed that for Browns, the distribution of segregation differed based on the racial composition of the context. Specifically, while it is common for Browns to occupy an intermediary social position relative to Blacks and Whites, the relative position of Browns in our sample was more or less distinct from Blacks depending on the racial composition of the larger metropolitan area. For example, in Salvador, (Bahia) which is located in the Northeast region of Brazil and has the largest Black population in the country, the distribution of segregation for Browns was more distinct from Blacks ( $\mathrm{G}_{\mathrm{i}}{ }^{*}$ statistic mean scores for Browns: -1.61 vs. Blacks: -0.6). This was in contrast to Porto Alegre, (Rio Grande do Sul), a city located in the southern region of Brazil which has a much higher proportion of Whites compared to other regions $\left(\mathrm{G}_{\mathrm{i}}{ }^{*}\right.$ statistic mean scores for Browns: -0.25 vs. Blacks: 0.02). Here, the distribution of segregation among Browns was more similar to Blacks (see Supplemental Fig. 2a and 2b).

\subsection{Sample characteristics}

Individuals residing in highly segregated neighborhoods were slightly younger, less educated and had lower household incomes. They were also more likely to be current smokers, engage in less physical activity, consume more total calories per day and were more likely to be obese. Perceptions of the neighborhood physical, food and social environments were generally worse in highly segregated neighborhoods (see Table 1). Compared to those without hypertension and diabetes, individuals with hypertension and diabetes were older, less educated and had lower household incomes. They were also more likely to consume high amounts of alcohol, more total calories per day and were more likely to be obese (see Supplemental Table 2).

\subsection{Adjusted prevalence of hypertension and diabetes}

Age and gender adjusted prevalence of hypertension and diabetes in the overall sample was $33 \%$ and $17 \%$, respectively. Adjusted prevalence of hypertension was highest among Blacks (48\%) and lowest among Whites (28\%). Similar patterns were observed for diabetes (Blacks: 26\%; Browns: 18\%; and Whites: 13\%). Adjusted prevalence for both hypertension and diabetes according to segregation and cross-classified categories of segregation and race are shown in Fig. 2a and b. Higher prevalence of hypertension and diabetes were observed in the most segregated neighborhoods compared to the least segregated neighborhoods (Hypertension: $42 \%$ vs. $29 \%$; Diabetes: $25 \%$ vs. $13 \%$ ). Cross-classified categories of segregation and race revealed similar patterns for both hypertension and diabetes such that Blacks, Browns, and Whites residing in highly segregated neighborhoods had a higher prevalence compared to those residing in the least segregated neighborhoods (see Fig. 2a and b). Moreover, Blacks had the highest prevalence of hypertension and diabetes prevalence irrespective of segregation.

\subsection{Multivariable logistic regression results}

In multivariable logistic regression models (Table 2), we found a positive association between segregation and both hypertension and diabetes after adjustment for demographic characteristics such that higher levels of segregation was associated with an increased odds of hypertension and diabetes (Hypertension: OR: 1.10, 95\% CI: 1.07, 1.12; Diabetes: OR: 1.12 95\% CI: 1.09, 1.15 per one unit increase in segregation). Further adjustment for per capita household income and educational attainment attenuated associations, but they remained statistically significant (Hypertension: OR: 1.05, 95\% CI: 1.03, 1.08; Diabetes: OR: 1.07, 95\% CI: 1.04, 1.10). Addition of perceived neighborhood conditions and behavioral and biological risk factors that may mediate the association between segregation and risk factors did not attenuate associations. In models that included segregation as a categorical variable (Supplemental Table 3), we found that individuals living in highly segregated neighborhoods had a higher odds of hypertension and diabetes compared to those living in the least segregated neighborhoods (Hypertension: OR: 1.26, 95\% CI: 1.09, 1.44; Diabetes: OR: 1.50, 95\% CI: 1.27-1.76). Finally, interactions between segregation and race were not statistically significant. 
Table 1

Select baseline characteristics overall and by Categories of residential segregation in ELSA-Brasil (2008-2010).

\begin{tabular}{|c|c|c|c|c|c|}
\hline & ELSA & High & Medium & Low & p-value \\
\hline No. of Participants & 10,617 & 1534 & 3173 & 5910 & \\
\hline Prevalent Hypertension, \% & 35.9 & 43.3 & 38.2 & 32.7 & $<\mathbf{0 . 0 0 0 1}$ \\
\hline Prevalent Diabetes, \% & 18.6 & 26.0 & 20.8 & 15.5 & $<\mathbf{0 . 0 0 0 1}$ \\
\hline Age in yrs, mean (SD) & $52.5(9.2)$ & $51.7(8.7)$ & $51.3(8.7)$ & $53.3(9.4)$ & $<0.0001$ \\
\hline Sex, $\%$ & & & & & 0.0001 \\
\hline Female & 56.0 & 51.2 & 55.9 & 57.2 & \\
\hline Male & 44.0 & 48.8 & 44.1 & 42.8 & \\
\hline Race, \% & & & & & $<0.0001$ \\
\hline Black & 15.9 & 28.6 & 22.0 & 9.3 & \\
\hline Brown & 28.1 & 39.3 & 34.1 & 22.0 & \\
\hline White & 56.0 & 32.1 & 43.8 & 68.8 & \\
\hline Educational Attainment, \% & & & & & $<0.0001$ \\
\hline Incomplete Primary & 4.5 & 10.7 & 7.3 & 1.4 & \\
\hline Complete Primary & 5.6 & 11.8 & 8.6 & 2.5 & \\
\hline Complete Secondary & 31.2 & 52.6 & 44.4 & 18.4 & \\
\hline University Degree & 58.7 & 24.9 & 39.7 & 77.7 & \\
\hline Per Capita Income \$R, mean (SD) & $1907(1511)$ & $1079(910)$ & $1366(1086)$ & $2412(1632)$ & $<\mathbf{0 . 0 0 0 1}$ \\
\hline Current Smoker, \% & 12.3 & 14.8 & 14.2 & 10.7 & $<\mathbf{0 . 0 0 0 1}$ \\
\hline High Alcohol Use, \% & 5.9 & 5.9 & 5.5 & 6.2 & 0.3929 \\
\hline Physical Activity, minutes per week, \% & & & & & $<\mathbf{0 . 0 0 0 1}$ \\
\hline No Physical Activity & 57.9 & 67.5 & 64.6 & 51.9 & \\
\hline$<150$ & 26.0 & 19.0 & 21.2 & 30.3 & \\
\hline$\geq 150$ & 16.1 & 13.6 & 14.1 & 17.8 & \\
\hline Total Calories in kcal, mean (SD) & $2933(1218)$ & 3308 (1429) & $3092(1353)$ & $2750(1034)$ & $<0.0001$ \\
\hline Daily Fat in g, mean (SD) & $93.4(43.7)$ & $102.2(51.1)$ & $96.8(47.3)$ & $89.3(38.9)$ & $<\mathbf{0 . 0 0 0 1}$ \\
\hline Obesity Status, \% & 22.1 & 26.3 & 24.6 & 19.6 & $<0.0001$ \\
\hline Local $\mathrm{G}_{\mathrm{i}}^{*}$ Statistic, mean (SD) & $-1.49(2.16)$ & $1.63(0.53)$ & $0.01(0.56)$ & $-3.10(1.35)$ & $<0.0001$ \\
\hline Neighborhood Food Environment & $1.89(0.96)$ & $2.25(1.05)$ & $2.14(1.05)$ & $1.66(0.82)$ & $<0.0001$ \\
\hline Neighborhood Walking Environment & $2.34(0.80)$ & $2.56(0.82)$ & $2.49(0.83)$ & $2.19(0.75)$ & $<\mathbf{0 . 0 0 0 1}$ \\
\hline Neighborhood Social Cohesion & $2.53(0.72)$ & $2.61(0.74)$ & $2.57(0.72)$ & $2.49(0.71)$ & $<0.0001$ \\
\hline Neighborhood Violence & $1.65(0.57)$ & $1.82(0.64)$ & $1.71(0.61)$ & $1.57(0.51)$ & $<0.0001$ \\
\hline
\end{tabular}

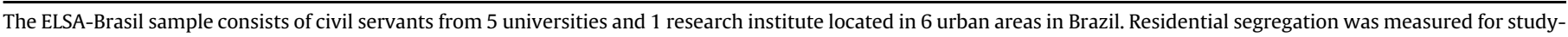

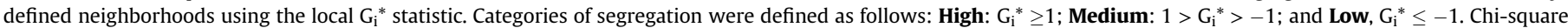
statistics were used to test for associations for categorical variables. Kruskal-wallis statistics were used to test for associations for continuous variables.

\section{Discussion}

In the first large-scale epidemiologic investigation of residential segregation and health in Brazil, we found that individuals living in economically segregated neighborhoods were more likely to have hypertension and diabetes independent of income, education, and other socio-demographic factors. Specifically, individuals living in highly segregated neighborhoods were $26 \%$ more likely to have hypertension and 50\% more likely to have diabetes than individuals living in the most affluent areas. This finding supports our hypothesis that segregation influences hypertension and diabetes over and above individual socioeconomic status. Furthermore we found that Blacks, irrespective of segregation, had the highest prevalence of both hypertension and diabetes while Browns occupied an intermediary status that was slightly better than Blacks but worse than Whites. Though we did not observe any statistically significant racial differences in the associations, we found that Blacks and Browns in our sample were more likely to live in segregated neighborhoods than Whites. Moreover, we found suggestive descriptive evidence that for Browns, the degree of segregation was more or less distinct from Blacks depending on the racial composition of the larger metropolitan area. This may suggest that Browns living in areas that are predominantly White experience similar restrictions to economic and social mobility to Blacks, and as a consequence, reside in worse neighborhood environments. In short, these findings reflect the non-negligible racial patterning of economically segregated neighborhoods found across urban areas in our study and may implicate these settings and their underlying structural mechanisms as potential drivers of racial inequalities in health in Brazil.

Our findings are consistent with most studies that have linked residential segregation to worse health outcomes. The vast majority of epidemiologic studies examining segregation and health have been conducted in the U.S. and are typically based on race-based measures of segregation which tend to be strongly correlated with patterns of socio-economic segregation (Krieger, 2014). Furthermore, segregation has generally been assessed at the metropolitan level as opposed to smaller geographic units such as neighborhoods (Kershaw and Albrecht, 2015; Krieger, 2014). At the metropolitan-level, recent studies have found that increased segregation is associated with higher risk of hypertension and diabetes (Kershaw and Albrecht, 2015). However, findings for 


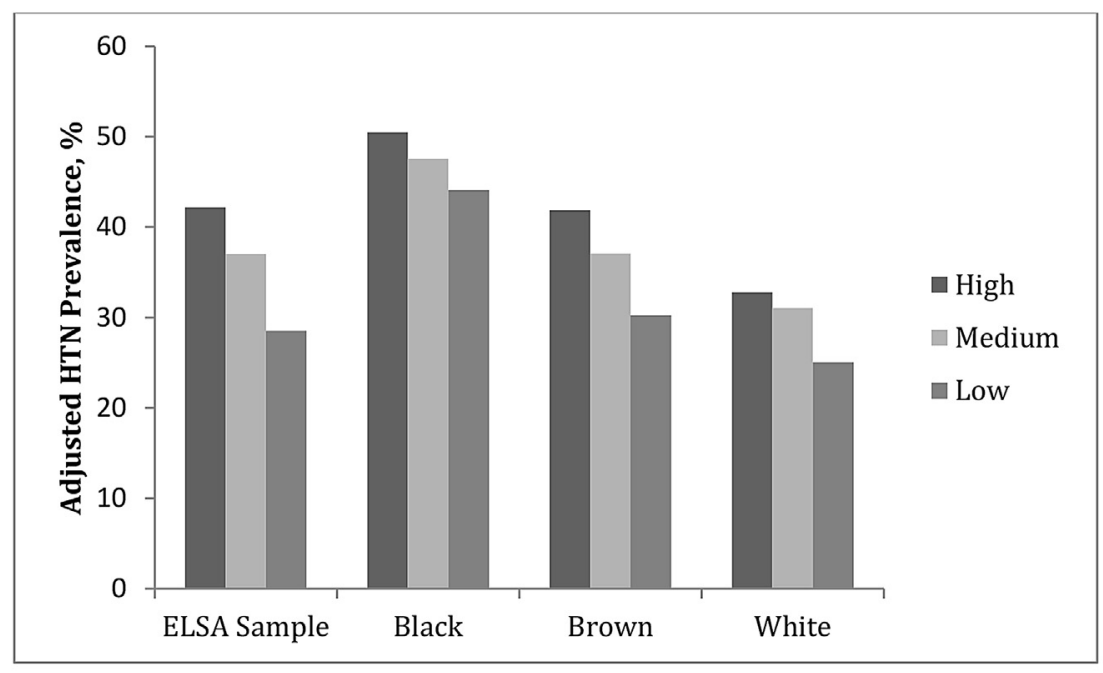

a

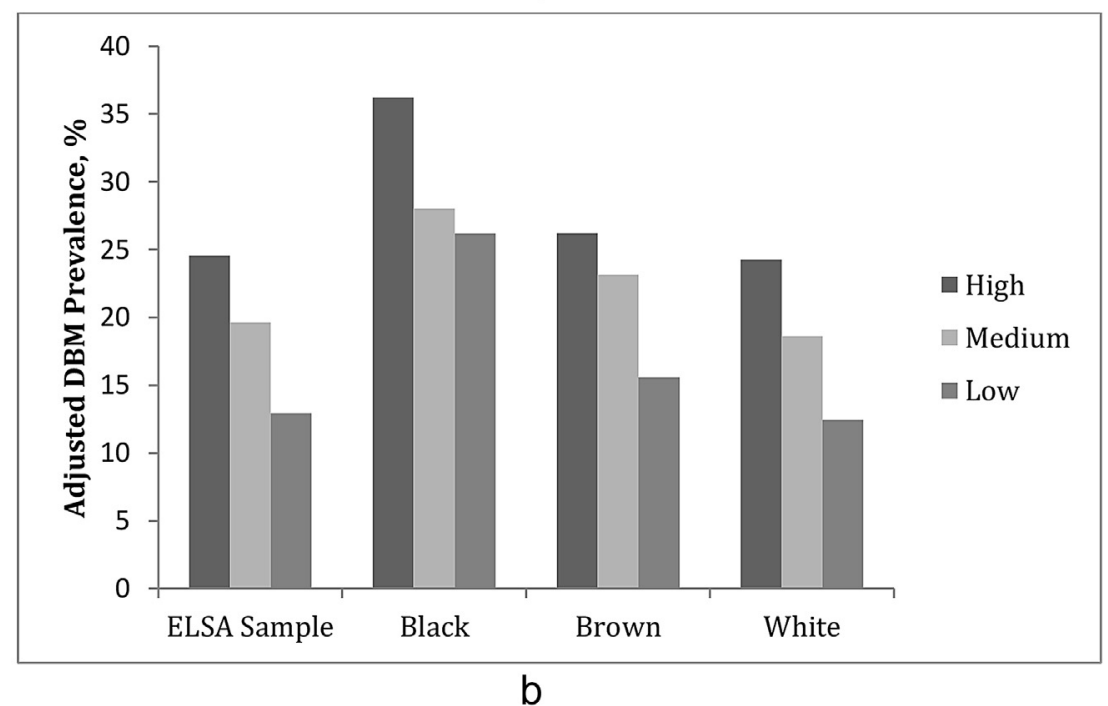

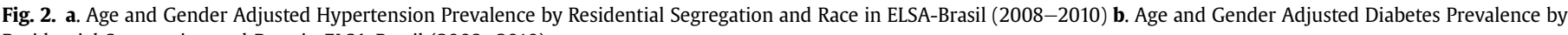
Residential Segregation and Race in ELSA-Brasil (2008-2010).

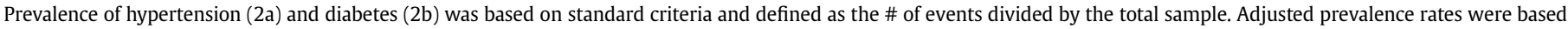

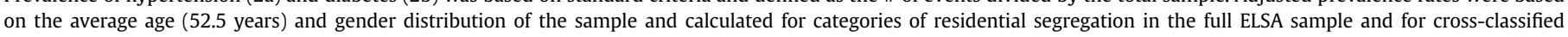
categories of residential segregation and race (Blacks, $n=1686$; Browns, $n=2984$; Whites, $n=5947$ ).

Table 2

Adjusted odds ratios (OR) and 95\% confidence intervals (CI) for Hypertension and diabetes prevalence corresponding to a one unit increase in residential segregation, ELSA-Brasil (2008-2010).

\begin{tabular}{llllll}
\hline & Hypertension & & & Diabetes & \\
\cline { 2 - 3 } & OR $(95 \% \mathrm{CI})$ & p-value & & OR $(95 \% \mathrm{CI})$ & $p$-value \\
\hline Model 1 & $1.10(1.07,1.12)$ & $<\mathbf{0 . 0 0 0 1}$ & & $1.12(1.09,1.15)$ & $<\mathbf{0 . 0 0 0 1}$ \\
Model 2 & $1.05(1.03,1.08)$ & $<\mathbf{0 . 0 0 0 1}$ & & $1.07(1.04,1.10)$ & $<\mathbf{0 . 0 0 0 1}$ \\
Model 3 & $1.05(1.03,1.08)$ & $<\mathbf{0 . 0 0 0 1}$ & & $1.07(1.04,1.11)$ & $<\mathbf{0 . 0 0 0 1}$ \\
Model 4 & $1.05(1.02,1.08)$ & $\mathbf{0 . 0 0 0 2}$ & & $1.07(1.04,1.11)$ & $<\mathbf{0 . 0 0 0 1}$ \\
\hline
\end{tabular}

Logistic regression models were used to estimate adjusted ORs and 95\% CIs. Residential segregation is included in models as a continuous variable. Model 1: Adjusts for age, gender, race, and study site; Model 2: Model $1+$ income and education; Model 3: Model $2+$ neighborhood characteristics; Model 4: Model $3+$ behavioral and biological risk factors.

Bold denotes statistical significance, $\mathrm{p}<0.05$.

neighborhood-level studies have been more varied. For example, in a recent review of studies on segregation and cardiovascular risk conducted between 2011 and 2014, Kershaw and Albrecht found that of the three studies conducted for hypertension and diabetes (Gaskin et al., 2014; Hunt et al., 2014; White et al., 2011), only one found a link to neighborhood-level segregation (Hunt et al., 2014). It should also be noted that although some investigators have suggested that segregation may provide protective effects for certain groups (e.g. ethnic enclaves) through increased social support/social capital or by serving as a buffer against interpersonal forms of discrimination (Bécares et al., 2012), our findings are most consistent with the majority of empirical studies which have found segregation to be detrimental to health and well-being.

Residential segregation is the spatial manifestation of entrenched racial and economic inequalities in Brazil. It is a striking and very visible feature of urban areas across the country and, as our findings suggest, has important implications for health and racial health inequalities. First, the spatial separation of individuals based on social class and race is not merely about the segregation of people, but also the segregation of economic and social resources 
necessary to achieve optimal health. In many instances, highly segregated neighborhoods are literally "cut-off" from access to formal job opportunities, education, and public infrastructure all of which are fundamental to health and well-being (Phelan et al., 2010; Williams and Collins, 2001). These settings also often lack health promoting resources such as access to healthy food, recreational and leisure activities as well as health services which further compromises the health of residents in these areas (Diez Roux and Mair, 2010). Moreover, the high concentration of poverty coupled with social ills such as higher rates of violence that tend to cluster in these settings (Minamisava et al., 2009; Santos et al., 2006) may be sources of stress that lead to unhealthy coping behaviors such as smoking and high alcohol use. These stressors may also activate the body's natural "fight or flight" mechanisms resulting in increased heart rate and blood pressure, as well as release of glucose into the blood stream. Chronic exposure to these settings may, over time, result in subsequent onset of hypertension and diabetes (Juster et al., 2010). In short, the deleterious neighborhood environments created by residential segregation become "embodied" (Krieger, 2011, p. 214) and manifest as poor health outcomes for individuals and populations.

Additionally, the systematic and disproportionate exposure of Blacks and Browns to economically segregated neighborhood environments reflects the long history of racial inequalities in Brazil and may be one form of structural racism that creates and perpetuates racial inequalities in health in the country. Though many often argue that, unlike the United States, Brazil did not enact formal laws to restrict the residential environments of Blacks and Browns, de facto practices and policies both inside and outside of the public sector have, in essence, created strikingly different residential environments for individuals of visible African descent. One driver of this phenomenon- supported by our data (Table 2 , Model 1 vs. Model 2) - is the compounded history of limited educational and economic opportunities afforded to Blacks and Browns which has stifled their economic and social mobility and relegated them to living in economically segregated residential environments. Affirmative action policies in the form of class and race-based "quotas" within the federal university system have only in recent years begun to redress these inequities. Moreover, there is evidence that Blacks and Browns experience discrimination in the labor market, regardless of their level of education and qualifications and therefore have lower chances of social mobility, including mobility out of segregated neighborhoods (Antônio and Ribeiro, 2006; Osorio, 2009; C. Ribeiro, 2012).

However, the overrepresentation of Blacks and Browns in economically segregated neighborhoods cannot solely be attributed to inequalities in social class (Telles, 2004b; Vargas, 2005). Empirical studies have found that Blacks, Browns and Whites from the middle classes and elites do not usually reside in the same neighborhoods (L. Ribeiro et al., 2009; Telles, 1992, 2004b). Thus, segregation in Brazil is also characterized by the near absence of Browns and especially Blacks from middle and high class neighborhoods. In other words, there is a phenomenon of "whitening" across socio-spatial hierarchies in Brazilian cities (Feldman, 2004; L. Ribeiro et al., 2009). This is quite evident in Rio de Janeiro for example: Though Whites make up only $50 \%$ of the population, they represent more than $80 \%$ of the residents of affluent neighborhoods such as Copacabana, Leme, Ipanema, Gávea, Jardim Botânico and Lagoa (Gusmão, 2015).

According to Edward Telles (2004b) the exclusion of middleclass Blacks and Browns from well-off neighborhoods arises from a combination of factors including discrimination in the formal real estate market, less access to credit, disparities in accumulated wealth, and discrimination from white upper class neighbors against Blacks and Browns. In fact, Browns and mostly Blacks who achieve social ascension often choose to remain in neighborhoods with higher concentration of Blacks and poor, where they have less access to urban infrastructure. This trend may limit their own social mobility since they do not fully participate in the higher classes' social networks (L. Ribeiro et al., 2009).

Other forms of institutional discrimination at both the state and local level reinforce racial homogeneity in the wealthiest areas of the city (Garcia, 2006; Rocha et al., 2016; Vargas, 2005). These include management of public transportation which has been used to systematically reduce the spatial mobility of the urban poor (Gomide, 2006; Pero and Stefanelli, 2015); high levels of hostility directed towards non-whites among the white upper classes (Figueiredo, 2004; Toste, 2014); and racial profiling practices among the police and private security services which transform middle and upper class areas into hostile territories for the poor and especially Blacks and Browns (Ramos and Musumeci, 2005). In summary, the combination of limited economic and social mobility coupled with discriminatory practices and policies has limited the residential environments of Blacks and Browns in Brazil resulting in poor health outcomes within this subset of the population.

Our study is not without limitations. First, its cross-sectional design limits the causal inferences that can be drawn. This also precludes a more robust empirical examination of the mechanisms that might explain the link between segregation and cardiometabolic risk factors in this population. For example, though we found descriptive empirical evidence that neighborhood conditions and behavioral risk factors were generally worse in highly segregated neighborhoods, inclusion of these factors did not attenuate associations as expected. This is consistent with other findings (Diez-Roux et al., 1997) in cross-sectional data and may reflect the limitations of using cross-sectional designs to explore these mechanisms. Thus, future studies in this setting should consider longitudinal study designs to improve causal inference and better delineate mediating mechanisms.

Additionally, though participants lived in their neighborhoods on average 17 years (median $=14$ ) this may not fully capture an individual's cumulative residential history over the lifecourse which could be more closely related to hypertension and diabetes onset. As with other observational studies examining neighborhood effects on health, our study is prone to selection bias such that individuals might be selected into neighborhoods based on individual attributes (e.g. individual SES or behavioral risk factors) that may also be related to hypertension and diabetes (Oakes, 2004, 2006). Finally, the ELSA sample includes civil servants who are employed at universities and research institutes and does not include individuals at the very extremes of the Brazilian income distribution, namely the very rich and the very poor. Thus, the sample is not fully representative of the Brazilian population. It is plausible that this limited the range of segregation in our sample and could have affected our estimates of associations if patterns are not the same across the full continuum of segregation. Moreover, Blacks and Browns in the sample may represent a "healthy subset" which may have limited our ability to observe racial differences in the association we expected. This underscores the need for future studies using population-based samples.

Our study also has important strengths. To our knowledge this is the first epidemiologic study to examine the link between segregation and chronic disease outcomes in Brazil. We do so in one of the largest, multi-site cohort studies of adult health that has ever been conducted in Brazil that includes participants from six diverse urban areas. ELSA-Brasil is also the first multi-site cohort study in Latin America to include biological, socio-demographic and behavioral data as well as perceived contextual characteristics. Additionally, our assessment of segregation was based on a novel spatial approach that allowed us to capture more fully the spatial 
patterning of segregation and to incorporate, empirically, information on the metropolitan area in which the neighborhoods were embedded. We further elucidate the patterning of cardio-metabolic risk factors by both segregation and race which adds to the small, but growing, empirical literature on race and health in Brazil.

\section{Conclusion}

In racially-stratified contexts like Brazil, "place and race" often intersect to create deleterious residential environments that are harmful to health and well-being and disproportionately impact marginalized racial groups. Our findings support this premise and provide empirical evidence that residential segregation may be an important structural determinant of cardio-metabolic risk factors and may contribute to racial health inequalities in this Latin American country. Efforts to eliminate racial health inequalities in Brazil will thus require sustained cross-sectoral and multi-level approaches to improve economic and social conditions for residents in these settings.

\section{Acknowledgements}

This research was supported by the Center for Integrative Approaches to Health Disparities funded by National Institute of Minority Health and Health Disparities P60 MD002249 (PI: Dr. Diez Roux) and the Drexel University Dornsife School of Public Health Urban Health Collaborative. The ELSA-Brasil baseline study was supported by the Brazilian Ministry of Health (Science and Technology Department) and the Brazilian Ministry of Science and Technology (Financiadora de Estudos e Projetos and CNPq National Research Council) (grants 01060010.00 RS, 01060212.00 BA, 0106 0300.00 ES, 0106 0278.00 MG, 01060115.00 SP, 01060071.00 RJ). A special thank you to all ELSA-Brasil participants.

\section{Appendix A. Supplementary data}

Supplementary data related to this article can be found at http:// dx.doi.org/10.1016/j.socscimed.2017.05.047.

\section{References}

Angotti, T., 1996. Latin american urbanization and planning: inequality and unsustainability in North and South. Lat. Am. Perspect. "Urban Question” Lat. Am. 23, 12-34.

Antônio, C., Ribeiro, C., 2006. Classe, raça e mobilidade social no Brasil. Dados 49 40 .

Aquino, E.M., Barreto, S.M., Bensenor, I.M., Carvalho, M.S., Chor, D., Duncan, B.B. et al., 2012. Brazilian longitudinal study of adult health (ELSA-Brasil): objectives and design. Am. J. Epidemiol. 175, 315-324.

Bécares, L., Shaw, R., Nazroo, J., Stafford, M., Albor, C., Atkin, K., et al., 2012. Ethnic density effects on physical morbidity, mortality, and health behaviors: a systematic review of the literature. Am. J. Public Health 102, e33-e66.

Bensenor, I.M., Griep, R.H., Pinto, K.A., de Faria, C.P., Felisbino-Mendes, M., Caetano, E.I., et al., 2013. Rotinas de organização de exames e entrevistas no centro de investigação ELSA-Brasil. Rev. Saúde Pública 47, 37-47.

Brazil Health Ministry, 2013. Information in Health - Vital Statistics.

Chaix, B., 2009. Geographic life environments and coronary heart disease: a literature review, theoretical contributions, methodological updates, and a research agenda. Annu. Rev. Public Health 30, 81-105.

Chor, D., Alves, M.G.d.M., Giatti, L., Cade, N.V., Nunes, M.A., del Molina, M.C.B., et al., 2013. Questionário do ELSA-Brasil: desafios na elaboração de instrumento multidimensional. Rev. Saúde Pública 47, 27-36.

Chor, D., Andreozzi, V., Fonseca, M.J., Cardoso, L.O., James, S.A., Lopes, C.S., et al. 2015a. Social inequalities in BMI trajectories: 8-year follow-up of the Pro-Saude study in Rio de Janeiro, Brazil. Public Health Nutr. 1-9.

Chor, D., Cardoso, L.O., Nobre, A.A., Griep, R.H., de Jesus Mendes, M.F., Giatti, L., et al, 2016. Association between perceived neighbourhood characteristics, physical activity and diet quality: results of the Brazilian Longitudinal Study of Adult Health (ELSA-Brasil). BMC Public Health 16, 1-11.

Chor, D., Pinho Ribeiro, A.L., Sa Carvalho, M., Duncan, B.B., Andrade Lotufo, P., Araujo Nobre, A., et al., 2015b. Prevalence, awareness, treatment and influence of socioeconomic variables on control of high blood pressure: results of the ELSA-
Brasil study. PLoS One 10, e0127382.

de Carvalho, I.M.M., Pereira, G., 2007. Introdução. Cad. CRH - Dossiê Dinâmica Metrop. Segregação Socioespacial 20, 261-279.

Diez-Roux, A.V., Nieto, F.J., Muntaner, C., Tyroler, H.A., Comstock, G.W., Shahar, E., et al., 1997. Neighborhood environments and coronary heart disease: a multilevel analysis. Am. J. Epidemiol. 146, 48-63.

Diez Roux, A.V., Mair, C., 2010. Neighborhoods and health. Ann. N.Y. Acad. Sci. 1186, $125-145$.

ESRI. How Hot Spot Analysis: Getis-Ord Gi* (Spatial Statistics) Works. http:// resources.esri.com/help/9.3/arcgisengine/java/gp_toolref/spatial_statistics tools/how_hot_spot_analysis_colon_getis_ord_gi_star_spatial_statistics_works. htm.

Feldman, S., 2004. A pesquisa sobre segregação: conceitos, métodos e medições. Espaços Debates 24, 87-109.

Figueiredo, A., 2004. Fora do jogo: a experiência dos negros na classe média brasileira. Cad. Pagu 23, 199-228.

Garcia, A., 2006. Desigualdades Raciais e Segregação Urbana em Antigas Capitais: Salvador, cidade d'Oxum e Rio de Janeiro, cidade de Ogum. Programa de PósGraduação em Planejamento Urbano e Regional Rio de Janeiro. Universidade Federal do Rio de Janeiro.

Gaskin, D.J., Thorpe, R.J., McGinty, E.E., Bower, K., Rohde, C., Young, J.H., et al., 2014. Disparities in diabetes: the nexus of race, poverty, and place. Am. J. Public Health 104, 2147-2155.

Getis, A., Ord, J.K., 1992. The analysis of spatial association by use of distance statistics. Geogr. Anal. 24, 189-206.

Gomide, A.A., 2006. Mobilidade urbana, iniqüidade e políticas sociais. IPEA. Políticas Sociais - acompanhamento e análise. 12, 242-250.

Gusmão, H., 2015. Mapa racial da cidade do Rio de Janeiro.

Hasenbalg, C., 1979. Discriminação e desigualdades raciais no Brasil Contemporâneo. Graal, Rio de Janeiro.

Hunt, B.R., Whitman, S., Henry, C.A., 2014. Age-adjusted diabetes mortality rates vary in local communities in a metropolitan area: racial and spatial disparities and correlates. Diabetes Care 37, 1279-1286.

IBGE, 2010. Atlas do Censo Demográfico Brasileiro 2010. Brasil Ministério do Planejamento, Orçamento e Gestão. Instituto Brasileiro de Geografia e Estatística.

Jargowsky, P., 2015. Architecture of Segregation: Civil Unrest, the Concentration of Poverty, and Public Policy. The Century Foundation.

Juster, R.P., McEwen, B.S., Lupien, S.J., 2010. Allostatic load biomarkers of chronic stress and impact on health and cognition. Neurosci. Biobehav Rev. 35, 2-16.

Kershaw, K., Albrecht, S., 2015. Racial/ethnic residential segregation and cardiovascular disease risk. Curr. Cardiovasc. Risk Rep. 9, 1-12.

Kershaw, K., Osypuk, T.L., Do, D.P., De Chavez, P.J., Diez Roux, A.V., 2015. Neighborhood-level racial/ethnic residential segregation and incident cardiovascular disease: the multi-ethnic study of atherosclerosis. Circulation 131, 141-148.

Kramer, M., Hogue, C., 2009. Is segregation Bad for your health? Epidemiol. Rev. 31, $178-194$.

Krieger, N., 2006. A century of census tracts: health \& the body politic (1906-2006). J. Urban Health 83, 355-361.

Krieger, N., 2011. Epidemiology and the People's Health: Theory and Context. Oxford University Press.

Krieger, N., 2014. Discrimination and health inequities. Int. J. Health Serv. 44, 643-710.

Krieger, N., Waterman, P.D., Spasojevic, J., Li, W., Maduro, G., Van Wye, G., 2015. Public health monitoring of privilege and deprivation with the index of concentration at the extremes. Am. J. Public Health 106, 256-263.

Leal, C., Chaix, B., 2011. The influence of geographic life environments on cardiometabolic risk factors: a systematic review, a methodological assessment and a research agenda. Obes. Rev. 12, 217-230.

Lee, P.H., Macfarlane, D.J., Lam, T.H., Stewart, S.M., 2011. Validity of the international physical activity questionnaire short form (IPAQ-SF): a systematic review. Int. J. Behav. Nutr. Phys. Act. 8, 115.

Lim, S.S., Vos, T. Flaxman, A.D., Danaei, G., Shibuya, K., Adair-Rohani, H., et al., 2012. A comparative risk assessment of burden of disease and injury attributable to 67 risk factors and risk factor clusters in 21 regions, 1990-2010: a systematic analysis for the Global Burden of Disease Study 2010. Lancet 380, 2224-2260.

Maricato, E. 2010. The Statute of the peripheral city. In: Rossbach, C.S.C.A. (Ed.), The City Statute of Brazil: a Commentary. Ministério das Cidades e Aliança de Cidades, São Paulo, pp. 5-22.

Maricato, E., 2013. Vulnerability and risk in the metropolis of the periphery: everyday life in Brazil's cities. Progress. Plan. 28-30.

Marteleto, L.J., 2012. Educational inequality by race in Brazil, 1982-2007: structural changes and Shifts in racial classification. Demography 49, 337-358.

Massey, D.S., Denton, N.A., 1988. The dimensions of residential segregation. Soc. Forces 67, 281-315.

Massey, D.S., Denton, N.A., 1993. American Apartheid: Segregation and the Making of the Underclass. Harvard University Press.

Minamisava, R., Nouer, S.S., de Morais Neto, O.L., Melo, L.K., Andrade, A.L., 2009. Spatial clusters of violent deaths in a newly urbanized region of Brazil: highlighting the social disparities. Int. J. Health Geogr. 8, 66.

Molina, M.C., Bensenor, I.M., Cardoso Lde, O., Velasquez-Melendez, G., Drehmer, M. Pereira, T.S., et al., 2013. Reproducibility and relative validity of the food frequency questionnaire used in the ELSA-Brasil. Cad. Saude Publica 29, 379-389.

Mujahid, M.S., Diez Roux, A.V., Morenoff, J.D., Raghunathan, T., 2007. Assessing the measurement properties of neighborhood scales: from psychometrics to ecometrics. Am. J. Epidemiol. 165, 858-867. 
NCD-RisC, 2016. Worldwide trends in diabetes since 1980: a pooled analysis of 751 population-based studies with 4.4 million participants. Lancet 387, 1513-1530.

Oakes, J.M., 2004. The (mis)estimation of neighborhood effects: causal inference for a practicable social epidemiology. Soc. Sci. Med. 58, 1929-1952.

Oakes, J.M., 2006. Commentary: advancing neighbourhood-effects research-selection, inferential support, and structural confounding. Int. J. Epidemiol. 35, 643-647.

Osorio, R., 2009. A Desigualdade Racial de Renda no Brasil: 1976-2006. Sociologia. Universidade de Brasília, Brasília.

Pero, V., Stefanelli, V., 2015. A questão da mobilidade urbana nas metrópoles brasileiras. Rev. Econ. Contemp. 19, 36-402.

Phelan, J.C., Link, B.G., Tehranifar, P., 2010. Social conditions as fundamental causes of health inequalities: theory, evidence, and policy implications. J. Health Soc. Behav. 51 (Suppl. 1), S28-S40.

Ramos, S., Musumeci, L., 2005. Elemento suspeito: abordagem policial e discriminação na cidade do Rio de Janeiro. Civilização Brasileira, Rio de Janeiro.

Ribeiro, C., 2012. Skin Color Continuum, Social Mobility and "Whitening" in Brazil. IESP-UERJ, Rio de Janeiro.

Ribeiro, L., Katzman, R., 2008. A cidade contra a escola?: segregação urbana e desigualdades educacionais em grandes cidades da América Latina. Letra Capital FAPERJ IPPES, Rio de Janeiro Montevidéu.

Ribeiro, L., Rodrigues, J., Corrêa, F., 2009. Status, Cor e Desigualdades Socioespaciais nos Grandes Espaços Urbanos Brasileiros. Letra Capital, Rio de Janeiro.

Rocha, C., Candido, M., Toste, V., 2016. Fronteiras (in)visíveis: raça, gênero e os limites do direito à cidade. In: Rodrigues, T. (Ed.), O Rio que queremos: propostas para uma cidade inclusiva. Núcleo Piratininga de Comunicação, Rio de Janeiro, pp. 129-148.

Santos, S.M., Barcellos, C., Sá Carvalho, M., 2006. Ecological analysis of the distribution and socio-spatial context of homicides in Porto Alegre, Brazil. Health \& Place $12,38-47$

Santos, S.M., Chor, D., Werneck, G.L., 2010. Demarcation of local neighborhoods to study relations between contextual factors and health. Int. J. Health Geogr. 9, $1-15$.

Santos, S.M., Griep, R.H., Cardoso, L.O., Alves, M.G.d.M., Fonseca, M.d.J.M.d., Giatti, L. et al., 2013. Cross-cultural adaptation and reliability of measurements on selfreported neighborhood characteristics in ELSA-Brasil, 2013 (47), 9.

Schmidt, M.I., Duncan, B.B., Mill, J.G., Lotufo, P.A., Chor, D., Barreto, S.M., et al., 2015. Cohort profile: longitudinal study of adult health (ELSA-Brasil). Int. J. Epidemiol. 44, 68-75.
Telles, E.E., 1992. Residential segregation by skin color in Brazil. Am. Sociol. Rev. 57 $186-197$.

Telles, E.E., 1995. Structural sources of socioeconomic segregation in Brazilian metropolitan areas. Am. J. Sociol. 100, 1199-1223.

Telles, E.E., 2004a. Race in Another America: the Significance of Skin Color in Brazil. Princeton University Press, Princenton, NJ.

Telles, E.E., 2004b. Residential Segregation. Race in Another America: the Significance of Skin Color in Brazil. Princenton University Press.

Telles, E.E., 2014. Pigmentocracies: Ethnicity, Race, and Color in Latin America. The University of North Carolina Press, Chapel Hill.

Telles, E.E., Lim, L., 1998. Does it matter who answers the race Question? Racia classification and income inequality in Brazil. Demography 35 ( $\left.n^{\circ} 4\right), 465-474$

Theodoro, M., 2008. A formação do mercado de trabalho e a questão racial no Brasil. In: Theodoro, M., Jaccoud, L., Osório, R., Soares, S. (Eds.), As políticas públicas e a desigualdade racial no Brasil : 120 anos após a abolição. IPEA, Brasília pp. 15-44.

Torres, H.d.G., 2006. Residential segregation and public policies: São Paulo in the 1990 's. Rev. Bras. Ciências Sociais 2, 0.

Torres, P., Ribeiro, R., Sanches, T., 2016. Desenvolvimento urbano sustentável: o direito à cidade no Rio de Janeiro contemporâneo. In: Rodrigues, T. (Ed.), O Rio que queremos: propostas para uma cidade inclusiva. Núcleo Piratininga de Comunicação, Rio de Janeiro, pp. 54-81.

Toste, V., 2014. Tão longe, tão perto: pretos e pardos e o enigma racial brasileiro. Instituto de Estudos Sociais e Políticos. Universidade do Estado do Rio de Janeiro, Rio de Janeiro.

Vargas, J., 2005. Apartheid brasileiro: raça e segregação residencial no Rio de Janeiro. Rev. Antropol. 48, 75-131.

White, K., Borrell, L.N., 2011. Racial/ethnic residential segregation: framing the context of health risk and health disparities. Health Place 17, 438-448.

White, K., Borrell, L.N., Wong, D.W., Galea, S., Ogedegbe, G., Glymour, M.M., 2011 Racial/ethnic residential segregation and self-reported hypertension among USand foreign-born blacks in New York City. Am. J. Hypertens. 24, 904-910.

Williams, D.R., Collins, C., 2001. Racial residential segregation: a fundamental cause of racial disparities in health. Public Health Rep. 116, 404-416.

Wilson, W.J., 1987. The Truly Disadvantage: the Inner City, the Underclass and Socia Policy. University of Chicago Press.

Wilson, W.J., 2009. More than Just Race: Being Black and Poor in the Inner-city. W. W. Norton \& Company, Inc, New York, NY. 